\title{
Genotyperen en fenotyperen van epilepsie bij kinderen
}

Op woensdag 5 december 2018 promoveerde Danique Vlaskamp aan de Rijksuniversiteit Groningen op het proefschrift Genotyping and phenotyping epilepsies of childhood ${ }^{\mathrm{I}}$ Haar proefschrift bestaat uit twee delen. In het eerste deel wordt de opbrengst van genetisch onderzoek beschreven, zowel vanuit het perspectief van artsen als van patiënten en hun ouders. In het tweede deel worden genotype-fenotype correlatiestudies beschreven.

Epilepsie kan het beste worden geclassificeerd op basis van klinische kenmerken (fenotypering). Daarnaast kan naar de genetische oorzaak van de epilepsie gezocht worden met behulp van verschillende moleculaire technieken (genotypering). Het combineren van fenotype en genotype is een waardevolle manier om meer te leren over genetische epilepsie.

De laatste jaren wordt genetisch onderzoek bij patiënten met epilepsie steeds vaker uitgevoerd. Het is echter nog onvoldoende duidelijk wat de diagnostische opbrengst en de psychologische gevolgen van genetisch onderzoek zijn. Ook is bij veel nieuwe epilepsiegenen nog onbekend wat het volledige spectrum van klinische kenmerken is en waarom het fenotype varieert tussen kinderen met varianten in hetzelfde gen.

\section{Genetisch onderzoek: wat is het resultaat?}

Vlaskamp beschrijft in haar proefschrift de resultaten van een onderzoek naar de diagnostische opbrengst van microarray-onderzoek bij kinderen met epilepsie die het Universitair Medisch Centrum Groningen bezochten. Bij II\% van de met microarray onderzochte kinderen werd een variant gevonden die de epilepsie kon verklaren; de meesten van hen hadden symptomatische focale epilepsie. Het bleek dat de kinderen vaker werden geselecteerd voor microarrayonderzoek als ze ontwikkelings- of gedragsproblemen hadden of opvallende uiterlijke kenmerken (Vlaskamp et al., 2017). Microarray kan dus een waardevolle test zijn voor het opsporen van de oorzaak bij kinderen met epilepsie, met name als bijkomende problemen voorkomen.

Daarnaast onderzocht Vlaskamp met behulp van vragenlijsten de impact van het in Groningen gebruikte genetische traject, waarbij zowel vooraf als na afloop van het genetische onderzoek genetische counseling plaatsvindt, op patiënten of hun ouders. De uitkomstmaat hierbij was empowerment, een maat die weergeeft in hoeverre personen controle hebben over hun kennis, gedrag, emotie en besluitvorming ten aanzien van hun epilepsie. Ze vond dat patiënten en hun ouders meer empowerment hadden na het genetisch counseling traject. De empowerment bleek al toe te nemen na het eerste counselinggesprek voorafgaand aan het genetisch onderzoek, wat het belang van pre-test counseling benadrukt. Omdat het een kleine pilotstudie betrof is vervolgonderzoek nodig om verder na te gaan of de aard van de testuitslag nog van invloed hierop kan zijn.

\section{Genotype-fenotype studies}

In diverse genotype-fenotype correlatiestudies heeft Vlaskamp samen met anderen de verschillende fenotypes onderzocht van patiënten met een variant in de genen SYNGAP1, GRIN2A en PCDH19 (Vlaskamp et al., 20I9c, Strehlow et al. 20I9, Vlaskamp et al., 20Iga). Deze studies kunnen helpen bij het eerder herkennen van deze vormen van epilepsie aan de hand van het fenotype. SYNGAP1mutaties leiden tot epileptische encefalopathie, waarbij epilepsie met ooglidmyoclonieën en myoclonisch-atone aanvallen samengaan, en aanvallen kunnen worden getriggerd door te eten (Vlaskamp et al., 20I9c). Voor GRIN2A werd aangetoond dat de aard en locatie van de variant in het GRIN2A-gen de ernst van het fenotype bepaalt. Patiënten met een ernstiger fenotype (epileptische encefalopathie en afasie) hebben meestal specifieke missense varianten in bepaalde domeinen van het eiwit met een gainof-function effect. Varianten in andere eiwitdomeinen, met een loss-of-function effect, werden voornamelijk gezien bij patiënten met een relatief milder fenotype (spraakstoornis en/of epilepsie met milde tot geen ontwikkelingsproblemen) (Strehlow et al., 20I9). Deze kennis over genotypefenotype relaties zou op termijn kunnen bijdragen aan het voorspellen van de ernst van het fenotype en het effect van medicatie. In een ander onderzoek bleek dat $21 \%$ van de 


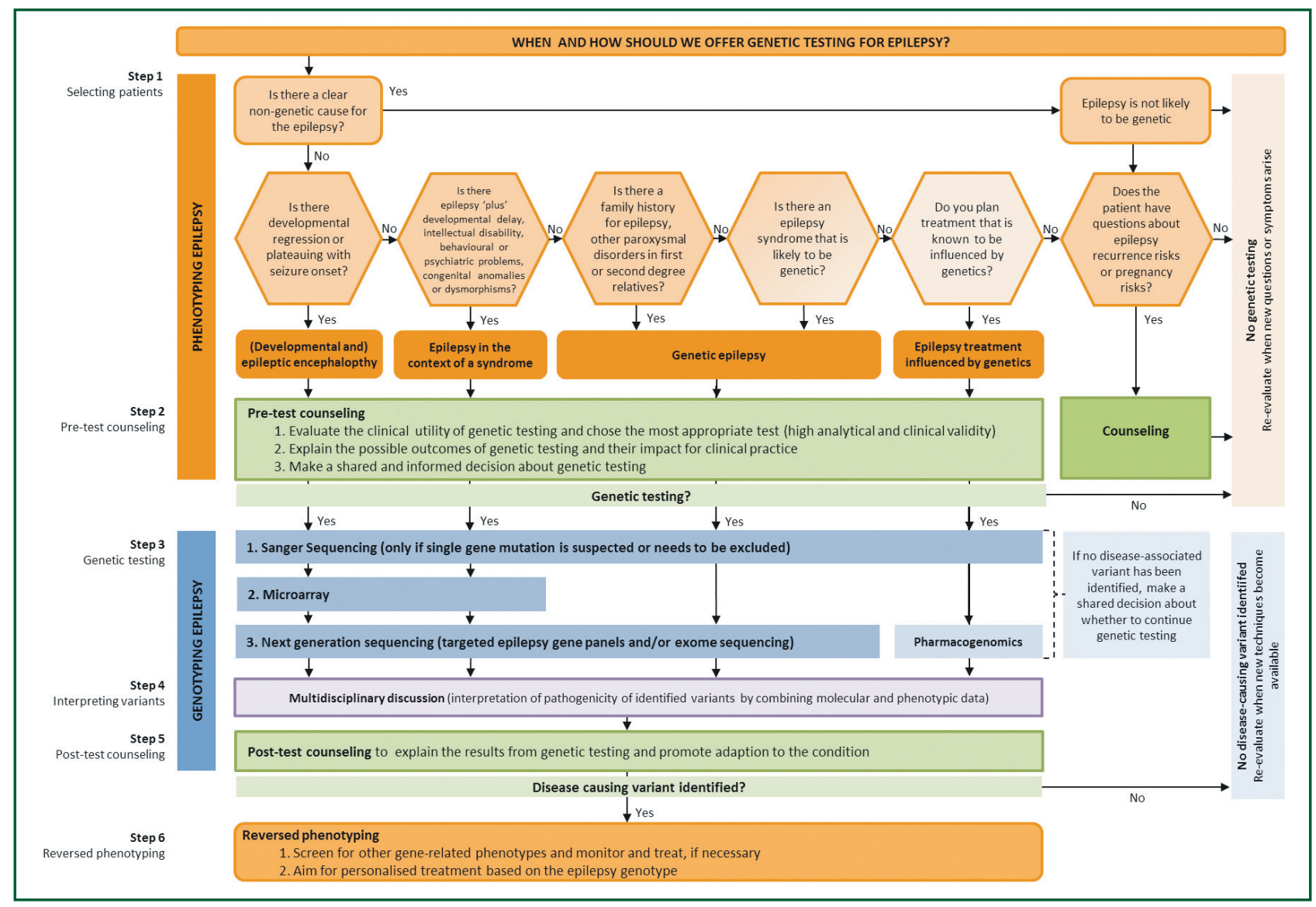

Figuur 1 Voorstel voor een diagnostisch stappenplan voor genetische diagnostiek bij patiënten met epilepsie

onderzochte vrouwen met PCDH19-gerelateerde epilepsie een psychotische stoornis, waaronder schizofrenie, ontwikkelt op jongvolwassen leeftijd (Vlaskamp et al, 2019a). Het is belangrijk om dit in de counseling te benoemen bij patiënten met deze epilepsievorm.

Verder is onderzocht of het fenotype verschilde tussen mensen met een variant in het PRRT2-gen en mensen met een deletie van chromosoom I6pII.2 inclusief het PRRT2gen (Vlaskamp et al., 2019b). Hierbij werd verwacht dat I6PII.2 deleties geassocieerd zijn met PRRT2-gerelateerde fenotypes, omdat deleties en de onderzochte sequentie varianten in het PRRT2-gen beide leiden tot loss-of-function. Het bleek dat de mensen met een deletie veel minder vaak PRRT2-gerelateerde symptomen hadden (benigne infantiele epilepsie en paroxysmale kinesiogene dyskinesie). Het is denkbaar dat verlies van andere genen in de deletie een beschermende werking heeft op het fenotype, maar daar bestaat geen bewijs voor. Het verschil wordt mogelijk verklaard door de wijze waarop de patiënten voor analyse zijn geselecteerd. Bij patiënten met een PRRT2-variant gebeurde dat op basis van hun epilepsie of bewegingsstoornis, terwijl bij degenen met een deletie meestal andere problemen, zoals een ontwikkelingsstoornis, de aanleiding waren. Het percentage van de patiënten bij wie een PRRT2-variant leidt tot klinische verschijnselen wordt mogelijk overschat door deze wijze van selectie.

\section{Diagnostisch stappenplan}

In het slothoofdstuk van haar proefschrift doet Vlaskamp een voorstel voor een diagnostisch stappenplan voor genetische diagnostiek bij patiënten met epilepsie (figuur I) op basis van de onderzoeksresultaten uit haar proefschrift en ervaringen in de klinische praktijk. Dit kan artsen helpen in hun besluitvorming wanneer en hoe genetisch onderzoek kan worden ingezet bij patiënten met epilepsie. Het algoritme kan helpen bij het beantwoorden van drie belangrijke vragen: welke patiënten dienen geselecteerd te worden voor genetisch onderzoek, welke genetische onderzoeken dienen uitgevoerd te worden en hoe dient de counseling te verlopen? Vlaskamp adviseert een selectieproces van patiënten bij wie de opbrengst op basis van het fenotype waarschijnlijk het hoogst is (stap I) en een goede counseling voorafgaand aan (stap 2) en volgend op (stap 5) het genetisch onderzoek (stappen 3 en 4). Post-test counseling (stap 5) is essentieel en helpt patiënten en hun families de medische, psychische en persoonlijke implicaties van de uitslag van het genetisch onderzoek te begrijpen en hiermee om te gaan. Wanneer een genetische verklaring voor de epilepsie gevonden is, dient opnieuw gekeken te worden naar het fenotype van de patiënt (reversed phenotyping, stap 6), inclusief eventuele comorbiditeit, om de juiste behandeling in te zetten en de prognose voor de patiënt en zijn/haar familie te verbeteren. Wanneer geen genetische verklaring is gevonden, 


\section{Proefschriftbesprekingen}

zou het nog steeds om een genetische epilepsie kunnen gaan.

Tot slot

Nieuwe lab-technische ontwikkelingen en toenemend inzicht in de betekenis van aanvankelijk als polymorfisme, variant of unknown significance geduide sequenties, kunnen later alsnog leiden tot een genetische diagnose. Andersom zou echter ook van een als oorzakelijk vastgestelde sequentievariant later kunnen blijken dat deze niet pathogeen is, of slechts een cofactor bij een andere hoofdoorzaak.

\section{Referenties}

Strehlow V, Heyne HO, Vlaskamp DRM, Marwick KFM, Rudolf G, de Bellescize J, Biskup S, Brilstra EH, Brouwer OF, Callenbach PMC et al. (20I9) GRIN2Arelated disorders: genotype and functional consequence predict phenotype. Brain. 2019;142:80-92.

Vlaskamp DRM, Bassett AS, Sullivan JE, Robblee J,

Sadleir LG, Scheffer IE, Andrade DM (20I9)

Schizophrenia is a later-onset feature of PCDHrg Girls

Clustering Epilepsy. Epilepsia 2019;60:429-440. (a)

Vlaskamp DRM, Callenbach PMC, Rump P, Giannini

LAA, Brilstra EH et al. (20I9) PRRT2-related pheno-

types in patients with a I6pri.2 deletion. Eur J Med Genet. 2019;62:265-269. (b)

Vlaskamp DRM, Callenbach PMC, Rump P, Giannini

LAA, Dijkhuizen T, Brouwer OF, van Ravenswaaij-Arts

CMA (2017) Copy number variation in a hospital-based cohort of children with epilepsy. Epilepsia Open

2017:2:244-254.

Vlaskamp DRM, Shaw BJ, Burgess R, Mei D, Montomoli $M$ et al. (2019) SYNGAPI encephalopathy: A distinctive generalized developmental and epileptic encephalopathy. Neurology 2019;92:eg6-e107. (c)

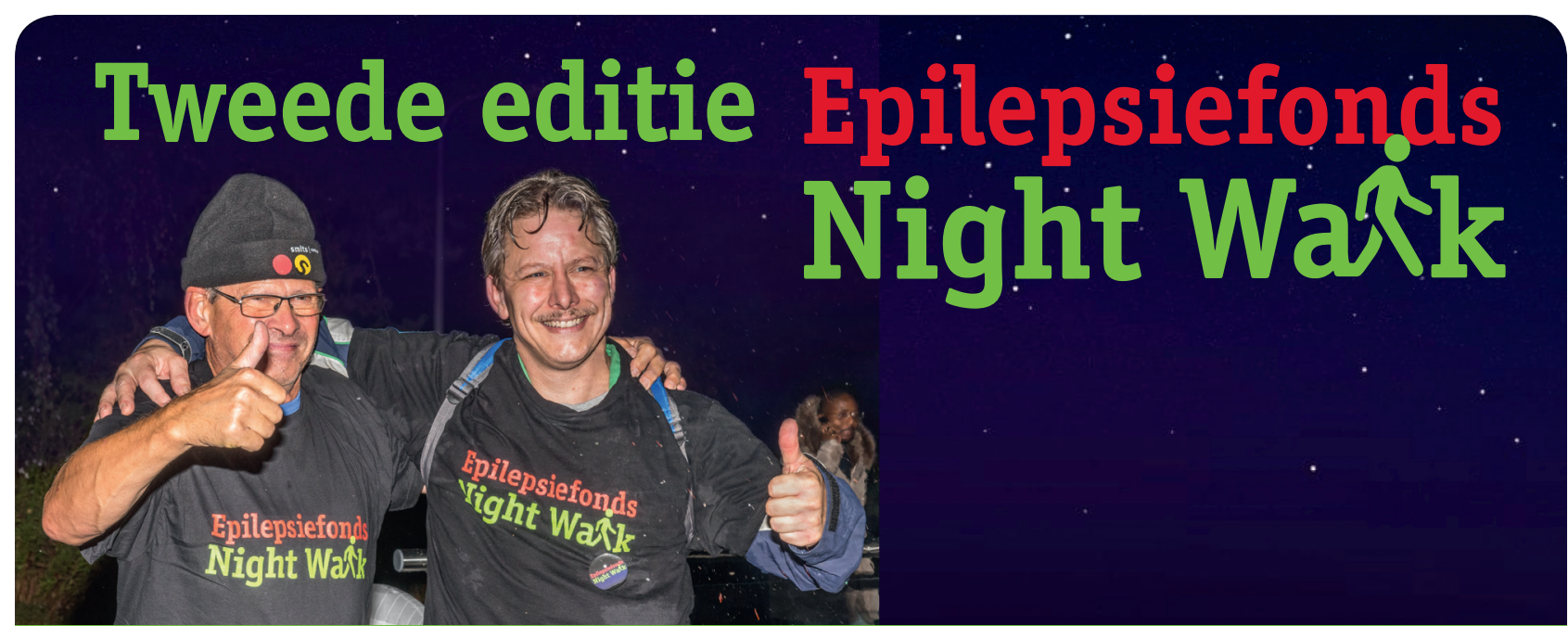

Na een geslaagde editie in 2018 organiseert het Epilepsiefonds dit jaar de tweede editie van de Epilepsie Night Walk. Op zaterdagavond 2 november is het zover en gaan we in het donker wandelen in Bunnik. Deelnemers kunnen zich, net als vorig jaar, laten sponsoren om geld op te halen voor epilepsieonderzoek.

Vorig jaar was de Epilepsie Night Walk een groot succes. Toen maakten meer dan
350 mensen gezamenlijk een mooie wandeltocht door het donker. Daar bouwen we op voort, vanuit een nieuwe locatie.

Dit jaar vertrekken we vanuit Bunnik (bij Utrecht), wat ons de mogelijkheid biedt om door afwisselende landschappen te wandelen. Daarnaast kunnen we op deze locatie een groter aantal deelnemers ontvangen om de tocht mee af te leggen.

\section{Loop jij 2 november mee?}

Ga naar www.epilepsienightwalk.nl en schrijf je in! Je kunt kiezen voor 3, 6, 10 of 15 kilometer. Als deelnemer betaal je $€ 19,95$ p.p., kinderen betalen een gereduceerd tarief. Door je te laten sponsoren, help je mee geld in te zamelen voor wetenschappelijk epilepsieonderzoek. 